\title{
Research of Contemporary Urban Complex from the Angle of Industry- City Integration
}

\author{
Wang Zihan*, Ren Pengyu and Ren Hong
}

Faculty of Construction Management and Real Estate, Chongqing University, No.174, Shazheng Street, Shapingba District, Chongqing, China

\begin{abstract}
Under the background of new urbanization and industry-city integration (I-C Integ. for short), this paper concerns about the rising phenomenon of large residential area and innovation industry, and suggests that the key of I-C Integ. is co-development of urban service industry with the two formers. Then, this paper reviews the concept of Urban Complex and its relationship with I-C Integ., and considers those two as one unified form by different scales of entire city and city-area. Furthermore, this paper put forward several types of Urban Complex basing on I-C Integ., and points out that area-industry will dominate the development of Urban Complex in the future.
\end{abstract}

Keywords: Contemporary urban complex, industry-city integration (I-C Integ.), innovation industry, large residential area, new urbanization, urban service industry.

\section{INTRODUCTION}

Industry-city integration is an important way to realize the coordination of urban construction and industrial development. Currently, there is development imbalance of industry and city in some cities and regions in our country, with coexisting situation of insufficient regional supporting industries and urban area hollow. How to balance the development between industry and city, and realize the mutual promotion of industrial development and urban construction, is one of the important issues in the process of new urbanization in China.

\section{INDUSTRY-CITY INTEGRATION ---- ERA PER- SPECTIVE OF URBAN DEVELOPMENT}

As China enters a new phase of urban sustainable development and industrial transformation and upgrading, the initial expansion mode that relies on traditional mining, energy and other industries has gradually fade out, but is turning to a new urbanization stage with coordinated development of industry, city and human. Industry-city integration has become an era perspective of China's urban development, and it will become one of the important evaluation dimensions of urban development level in the future $[1,2]$.

On the one hand, demand for industrial structure optimization, transformation and upgrading has led to the emergence of a number of advanced, knowledge innovation-based industries. It means that future urban industries will break through the limit of traditional distributed industrial park, and gradually form a cluster in the city centre, providing prerequisites for the complexity of adhesive industry and city carrier, with the characters of low carbon, information, innovation driven, etc [3-6].

On the other hand, the complex requirements of liveable and industry-appropriate city have led to the formation of the planning concept of the large settlement. Firstly, it emphasizes the hybrid of multiple functions in land planning, and through the layout of different industries, creates the diversification of jobs and residents, to realize occupation and residence balance in certain urban area. Secondly, apply the form of "big mixed habitation and small settlements", to form multiple habitation, which purpose is to underlying economic relations and functional complementation between different social strata. Thirdly, continuously improve urban public facilities and ancillary services, to allow certain region to play more complete urban functions. The planning idea of large settlement area provides a platform and carrier for the emerging industries and supports the integration of urban regional organism.

In the above, we have described the process of urban development, from the perspective of industry and city. The rise of new industries will provide the preconditions for industry-city integration, while re-organization of urban organic space provides material support for industry-city integration. However, the key link of industry-city integration lies in urban third industry (service and support) and its bonding effect on both. According to Petty - Clark Theorem, with the improvement of economic development level and the growth of per capita national income, share of secondary industry in GDP and relative proportion of labour will ascend; as economics further develop, employment absorption capacity of primary and secondary industries will be limited or even decline, while the relative proportion of the tertiary industry and labour will rise sharply, and its employment absorption capacity will continue to increase. Urban development experience of developed countries shows that, the proportion of tertiary industry in cities may occupy more 
than 70 percent of the city's overall economy [7-9]. Thus, industry-city integration is an important stage in the city towards maturity. Whether it can produce a good chemical reaction between industry and city will depend on the development of urban third industry and its synergy effect with the former two. It is far from enough for such integration effect to rely solely on the convergence condition of emerging industry, or platform vector of urban large settlement area. The only way is to build a "driver" of a relatively complete urban function in urban areas, and through suture bonding of urban third industry to lead and promote the process of industry-city integration in the region.

In the construction process of such "driver", urban complex plays a vital role, which organically integrates industry, community, service and other synergy elements in urban areas, to inject vitality for industry-city integration.

\section{THE CONCEPT OF URBAN COMPLEX BASED ON INDUSTRY-CITY INTEGRATION}

Generally, urban complex is generally summed up as the result of the development of urban agglomeration in academic. According to the traditional sense of understanding, urban complex is based on building groups, with three or above city multifunction units of commerce, office, hotel, apartment and entertainment. We think this definition is a bit narrow, too concerned about city commercial, service and residential supporting functions, but fail to integrate the industrial sector which acts as one of city constitution cores. In fact, the origin of the city started with industrial polymerization [10-12]. From the concentration of handicraft workshop in ancient times, to machine production in modern industrial revolution period, the birth and development of city depends on the agglomeration effect of industry, economic, and population. Under the background of the great development of China's contemporary industry-city integration, if urban complex misses the key element of industry, it will not be able to bear the important task of the times. Therefore, in this study, we try to carry out a new interpretation of urban complex, from the perspective of industry-city integration as follow:

Urban complex is a comprehensive property form based on agglomeration development of economic, industry, population and service. It is secondary micro-urban systems based on building groups, with a mixture of industrial, commercial, residential, supporting and other urban functions, and achieves coordinated development of a variety of factors rurmore, the above concepts of urban complex can be resolved as three main connations of mixed use, organic polymerization and cooperative emergence (Fig. 1).

\subsection{Mixed Use}

Firstly, urban complex reflects in mixed use of functions, that is: includes three kinds or above of profitable major formats and their mutual support; carry out space and functional integration organization various elements of the entirety, and make sure it is free from outside interference of internal transport links; set out to develop according to a clear plan. Mixed use aims at regional intensive land use, to realize coupling complementary of commerce, inhabitancy,

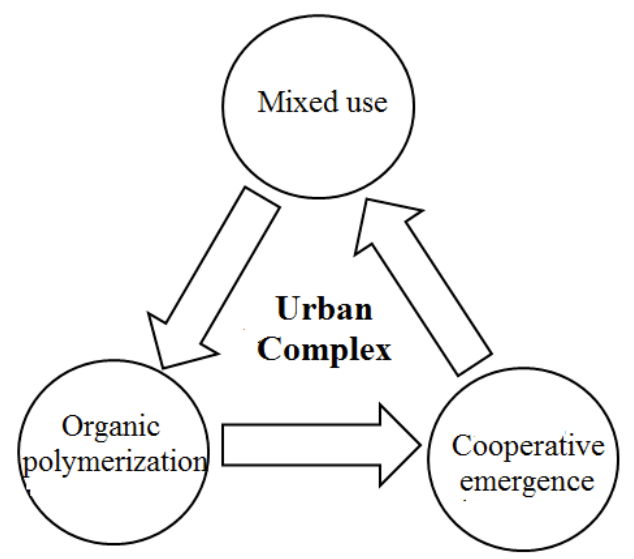

Fig. (1). Connotation of urban complex.

and industry in the urban area, of which essence is to provide coexistence and suture interface of industrial functions and urban functions within local area scale.

\subsection{Organic Polymerization}

Urban complex also reflects in the process of organic polymerization. Urban complex as an organic system, its elements of commerce, inhabitancy and industry can be adaptive in accordance with the functional division. Meanwhile, as the changes of the urban external environment, it can constantly adjust its own functions, and converges more coordinated development elements (such as various supporting facilities), to speed up the development process. Due to the complex nature and multivariate function, urban complex has a relatively complete regulatory mechanism and adaptive capacity, so that conducive to the formation of the growth pole effect in the region, and achieve rapid development of regional economy while integrating local industry and urban functions.

\subsection{Cooperative Emergence}

As a multiple functional unit of the micro city with the combined agglomeration, the value of urban complex lies in cooperative emergence. According to the theory of complex system and synergy, under certain conditions, an open system with multiple elements and complex structure can be continuously optimized and integrated, through the nonlinear interaction between the subsystems of the system, and eventually produce form synergy effect. It results in: the overall benefits of the system and its external environment is for more than the total value of all individual elements, that is, $1+1>>2$. It is just because of integration of urban total functional elements including industries that, it can realize comprehensive collaborative development of urban industry, economic, population, inhabitancy and supporting facilities.

\section{DIALECTICAL RELATION BETWEEN URBAN COMPLEX AND INDUSTRY-CITY INTEGRATION}

\subsection{Industry-City Integration is the Driver and Devel- opment Source of Urban Complex}

Industry-city integration is characteristic of the city developed to a certain stage of polymerization. Relationship 


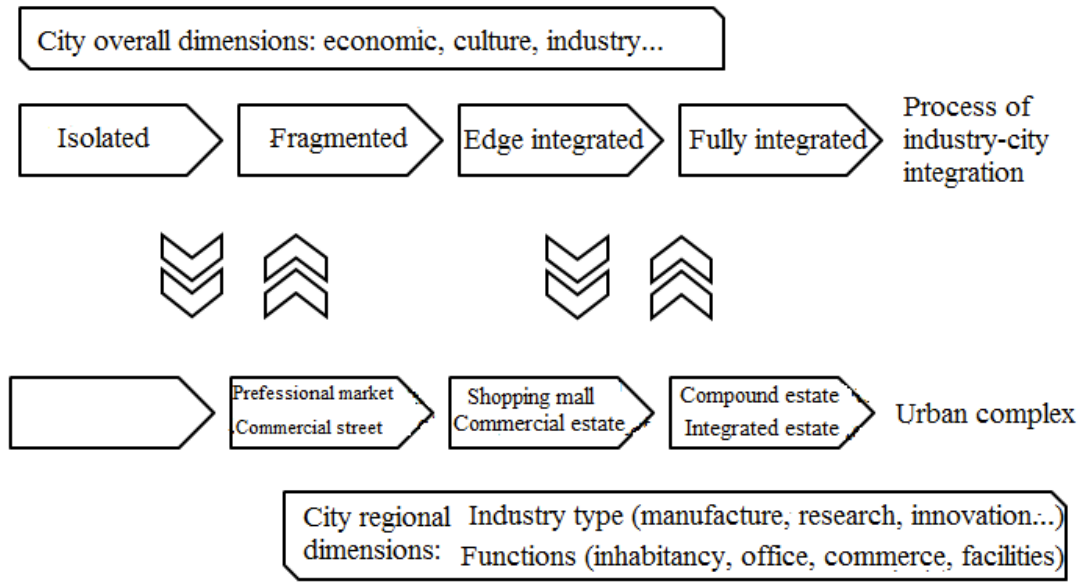

Fig. (2). Development of urban complex and industry-city integration process.

between industry and city can be summarized as three stages, that is, forming stage, growth stage and maturity stage. In early forming stage, industry and the city are in a loose state, and there are mainly traditional polluted and high energy consuming industries, which are far from urban residential areas, with low level urban facilities. Such separation situation of industry and city is difficult to form the structure of urban complex. As industrial agglomeration and industry chain is gradually extending upstream and downstream, industry surrounding environment gradually improved, and primary business and support services began to appear. Thus, urban residential land was setting nearby, and it entered into growth stage when industrial development supported urban expansion. With the integration and upgrading of new industries, cities began to provide services for industrial development, and industrial, residential, ancillary services were reunited, forming regional integration status of perfect facilities, thus it entered into maturity stage of industry-city integration. At this stage, the scope of urban complex further expands, reflecting as the pattern of "pan industry, multiple function and micro city", which really plays its effect of aggregation and bring about great regional synergy value (Fig. 2).

Thus it can be seen that, as one of the important evaluation Indices of urban development level, industry-city integration is the driver and development source of urban complex. Evolution of urban complex and change of industrycity relationship are corresponding to each other.

\subsection{Industry-City Integration is the Microscopic Carrier and Direct Embodiment of Urban Complex}

Urban complex has undergone development stages of professional market, commercial estate, complex estate, residential street, etc. As one of the conceived prototypes of urban complex, various professional markets are supporting properties surrounding the industry. Meanwhile in urban residential area, living supporting services also began to appear, gradually forming the commercial street. As regional industry and city interaction gradually brisk, scale of commerce initially expanded, and that is the first two generation of urban complex with large shopping centres. When the city development enters mature stage, it is blended with regional industries, and commercial estate begins to evolve into a composite estate. From HOPSCA (hotel, office, park, shopping, convention, apartment) to commercial property, it forms the integrated development situation of regional commerce, residence and industry, which takes various types of emerging urban industries as the leading role, improved urban commercial and service support as the basement, large mixed settlement areas as the carrier. The boundaries of the city complex began to blur, and gradually expand to the dimension of the urban area. Eventually, the concept of urban complex and regional industry-city integration tend to be unified.

\subsection{Urban Complex and Industry-City Integration are Unity in the Different-Dimension Development of City and Region}

As mentioned above, industry-city integration is to review the linkage between industry and city from the macro perspective of the city, while urban complex is to bring about synergy value by integrating regional resources, from the regional micro perspective. The relation between the both is similar to that of "point" and "plane". Actually, we can regard urban complex as some polar points distributing in urban areas. Along with the development and expansion of these polar points, the isolated industry, population, economy and other factors will be gradually optimized, hackled and stitched, and finally radiate industry-city integration to the whole area, so that achieve the unity of urban complex and industry-city integration. I think, it is consistent with the "growth pole effect" played by city polar nuclei, in Francois Perroux's growth pole theory, that is, urban complex and regional industry-city integration, urban agglomeration and regional economic agglomeration are isomorphic.

\section{DISCUSSION ON THE FORM OF URBAN COM- PLEX DEVELOPMENT BASED ON INDUSTRY-CITY INTEGRATION}

From a macro point of view, China's urban complex has evolved to the fourth generation so far: "professional market - commercial street - commercial estate - compound estate". Along with the process of industry-city integration, China's urban complex has developed the integrated form of commerce, inhabitancy and industry, which radiate regional in- 
dustries, attract regional agglomeration and provide urban support functions. Among them, new industries, knowledgebased industries and urban comprehensive service industries are gradually replacing the traditional business, and become the core development elements of modern urban complex.

\subsection{Urban Complex Taking New Industries and Knowl- edge Innovation as the Leading}

Such urban complex is involved from advanced and innovative industrial park, which is sustained by information, research, technology, office, etc. Because of the features of low-carbon, intelligence and innovation of industry itself, architectural functions, infrastructure, landscape and supporting of the park are blameless. With the maturity of industrial park, a large number of high-quality talents successively gather, and then all types of functional units along the park are developing rapidly. Sometimes Its periphery will even become a new urban sub centre area, such as Suzhou Jinji Lake District, Beijing Zhongguancun Software base,
Shenzhen Tian An Digital City, etc.

\subsection{Urban Complex Taking Headquarters Economy and Urban Finance as the Leading}

Such urban complex is involved from urban core commercial estate and compound estate, which is sustained by financial, trust, headquarters, etc. Its development level of commerce, inhabitancy and supporting is very high, belonging to the category of urban CBD. It has huge effects of radiation on Regional industry and even the whole city economy, so it is of great value. Representations of such urban complex are Shanghai Lujiazui financial centre, Chongqing Jiangbei mouth financial business district, etc.

\subsection{Urban Complex Taking Transport Hub and Logis- tics Business as the Leading}

Such urban complex is located in the urban transport hub area. Along with the rapid development of China's high

Table 1. Influencing factors of urban complex construction.

\begin{tabular}{|c|c|c|}
\hline Influencing Factors & First-Level Indicator & Second-Level Indicator \\
\hline \multirow{7}{*}{ Environment factors } & \multirow{4}{*}{ Land physical conditions $\mathrm{A}_{1}$} & Geological condition $\mathrm{B}_{1}$ \\
\hline & & Surface smoothness $\mathrm{B}_{2}$ \\
\hline & & Land accessibility $\mathrm{B}_{3}$ \\
\hline & & Land Visual effect $B_{4}$ \\
\hline & \multirow{3}{*}{ Land location $\mathrm{A}_{2}$} & Supporting infrastructure $\mathrm{B}_{5}$ \\
\hline & & Transportation convenience $\mathrm{B}_{6}$ \\
\hline & & Regional Value property $\mathrm{B}_{7}$ \\
\hline \multirow{5}{*}{ Economic factors } & \multirow{2}{*}{ Macroeconomic environment $\mathrm{A}_{3}$} & Investment policy $\mathrm{B}_{8}$ \\
\hline & & Financial market system $B_{9}$ \\
\hline & \multirow{3}{*}{ Microeconomic environment $\mathrm{A}_{4}$} & Residents purchasing power $\mathrm{B}_{10}$ \\
\hline & & Consumption habits $\mathrm{B}_{11}$ \\
\hline & & Competition $\mathrm{B}_{12}$ \\
\hline \multirow{8}{*}{ Social development factors } & \multirow{3}{*}{ Population status $\mathrm{A}_{5}$} & Population density $B_{13}$ \\
\hline & & Population quality $\mathrm{B}_{14}$ \\
\hline & & Population structure $\mathrm{B}_{15}$ \\
\hline & \multirow{2}{*}{ Social impact $\mathrm{A}_{6}$} & Environmental pollution $\mathrm{B}_{16}$ \\
\hline & & Land acquisition and demolition $\mathrm{B}_{17}$ \\
\hline & \multirow{3}{*}{ Emergency capability $\mathrm{A}_{7}$} & Emergency rescue capability $\mathrm{B}_{18}$ \\
\hline & & Emergency organization $\mathrm{B}_{19}$ \\
\hline & & Escaping evacuation capability $\mathrm{B}_{20}$ \\
\hline \multirow{3}{*}{ Policy factors } & Institutional environment $\mathrm{A}_{8}$ & Institutional environment $\mathrm{B}_{21}$ \\
\hline & Judicial environment $\mathrm{A}_{9}$ & Judicial environment $\mathrm{B}_{22}$ \\
\hline & Supervision strength $\mathrm{A}_{10}$ & Supervision strength $\mathrm{B}_{23}$ \\
\hline Historical and cultural factors & Historical and cultural factors $\mathrm{A}_{11}$ & History and culture $\mathrm{B}_{24}$ \\
\hline
\end{tabular}


speed rail and light rail transportation, the transport hub complex of compound industry types of hotel, apartment, shopping mall and so on are coming into being. Through the fusion of transport system and city facilities, it manages to bring about the agglomeration of urban service industry driven by traffic flow. On the other hand, with the rapid development of modern logistics industry, the intelligent commercial complex comes into being, which is a aggregation of specialized market cluster, exhibition trade mall, electronic network city, fourth party logistics and business comprehensive facilities. Typical cases of such urban complex include Chongqing Shapingba high-speed rail hub business centre (planning), Chengdu international IOT port, etc.

\subsection{Urban Complex Taking Higher Education and Cul- tural Tourism as the Leading}

The "university city" mode contributes to the university complex of industry, university and research. Because of the aggregation of high quality talents, it has extremely strong industry scalability. In addition, the culture and travel industrial complex which integrates tourism, cultural tasting, ecoresort and exhibition is also being explored. Representatives of the former include Chongqing University City, Changsha University City, etc. Representatives of the latter can be seen in many regional tourism scenic planning.

It is obvious from the classified elaboration above, in the development process of urban complex based on industrycity integration, along with the improvement of industrial agglomeration and industrial chain, its ability to integrate resource elements and coordinate the external environment will be further strengthened, and its radiation range will be expanded from the noumenon to surrounding and even the whole urban area. The urban complex originally scattered in urban area eventually complete the process of industry-city integration, and achieve the unity of urban complex and industry-city integration.

\section{FACTORS MODEL OF URBAN COMPLEX CON- STRUCTION}

\subsection{Factor Model}

Construction of urban complex is complex system engineering, which is similar to a miniature city, and there are many influencing factors. Some of the factors are easily perceived, such as hydrogeological situation of the land, complete extent of infrastructure, public transportation convenience, etc. However, there are some factors that need to be determined through investigation and analysis, such as purchasing power of local residents, service facilities status, etc. Moreover, many intangible values may also need to be considered, such as future traffic planning, proposed landmark building, etc. Overall, planning and construction of urban complex is a comprehensive process to weigh a variety of factors.

In this study, we divide the influencing factors of urban complex construction into environment factors, economic factor, social development factors, policy factors, historical and cultural factors, and each factor contains several sub factors. Here we establish the factors model of urban complex construction, as shown in Table 1.

Table 2. Reviews set and scores.

\begin{tabular}{|c|c|}
\hline Review & Score \\
\hline \hline Very bad & 1 \\
\hline Bad & 2 \\
\hline Medium & 3 \\
\hline Good & 4 \\
\hline Very good & 5 \\
\hline
\end{tabular}

\subsection{Expert Scoring}

In order to determine the evaluation value of each indicator, we adopt expert scoring method to determine the evaluation matrix. Firstly, we establish the reviews set and its corresponding scores as Table $\mathbf{2}$.

According to the expert's score, establish the evaluation matrix X:

$X=\left(x_{1}, x_{2}, \ldots, x_{m}\right)$

\subsection{Index Weight Determination}

There are many methods to determine the weight, which can be divided into subjective method (e.g. AHP, binary comparison, MCDM and expert survey, etc.) and objective method (entropy information method, factor analysis, etc.). Here we adopt combined assignment method, which is to integrate the weights by both subjective method and objective method, to determine the index weights.

$W_{i}=\alpha W_{i s}+\beta W_{i o}$

In the formula, $W_{i}$ is the combined weight of index $i ; W_{i s}$ is the weight by subjective method of index $i$, while $W_{i o}$ is its weight by subjective method. Generally, the weights of all the indices should satisfy the normalization condition and non-negativity condition:

$\sum_{i=1}^{m} W_{i}=1$

$W_{i}>0,(i=1,2, \cdots m)$

$\alpha$ and $\beta$ are linear coefficients of the combined weight vector, $\mathrm{a} \geq 0, \mathrm{~b} \geq 0$.

$\alpha=\sqrt{\left[1+\left(\frac{\sum_{i=1}^{n} \sum_{j=1}^{m}\left|x_{i j}-x_{i}^{\prime}\right| W_{i s}}{\sum_{i=1}^{n} \sum_{j=1}^{m}\left|x_{i j}-x_{i}^{\prime}\right| W_{i o}}\right)^{2}\right]}$

$\beta=1-\alpha$

Now, we obtain the weight matrix $W$ :

$W=\left(W_{1}, W_{2}, \ldots, W_{m}\right)^{T}$

6.4. Urban Complex Comprehensive Development Index 
Based on the valuation matrix $\mathrm{X}$ and weight matrix $\mathrm{W}$, we can calculate the comprehensive development index of urban complex $E$ as follow:

$$
E=X \cdot W=\left(x_{1}, x_{2}, \ldots, x_{m}\right) \cdot\left(W_{1}, W_{2}, \ldots, W_{m}\right)^{T}=\sum_{i=1}^{m} x_{i} \cdot W_{i}
$$

\section{CONCLUSION AND PROSPECT}

Urban complex is the product in the process of industrycity integration, and its development status directly reflects the maturity degree of industry-city integration within the city area. With the continuous consolidation of industry-city integration, urban complex will show a collaborative development trend of commerce-inhabitancy-industry integration, to promote the optimization and upgrading of regional industries and urban functions supporting [13-15].

Study on the urban complex based on industry-city integration is supposed to become one of the important measurements of regional economic, industry, population and facilities status. As for urban complex development evaluation system based on industry-city integration, and the innovative thinking in terms of planning, design, development mode and operational transformation is necessary for further research in the future.

\section{CONFLICT OF INTEREST}

The authors confirm that this article content has no conflict of interest.

\section{ACKNOWLEDGEMENTS}

Declared none.

\section{REFERENCES}

[1] D Ouyang, H. Li, and L. Li, "Industry-city integration in urban transition:sino-malaysia industrial park case," Planners, vol. 5, no. 4, pp. 101-110, 2014.
[2] W. Li, and Y. Zhang, "Industry-city integration from human consideration viewpoint," Planners, vol. 2, no. 1, pp. 110-115, 2014.

[3] B. Du, "Multiple analysis of industry-city integration, " Planners, vol. 2, no. 1, pp. 116-120, 2014.

[4] H. Wei, Q.Sun and Q.Wei, "Industry-city integration planning for capacity expansion, wuhua county," Planners, vol. 2, no. 1, pp. 131-136, 2014

[5] X. Wang, L. Su, and B. Guo, "Evaluation of industry-city integration of high-tech district based on factor analysis and cluster analysis," Science \& Technology Progress \& Policy, vol. 30, no. 16, pp. 26-29, 2013.

[6] M. Spence, Urbanization and Growth, World Bank, Washington D.C., 2009.

[7] C.Ding, and X. Zhao, Urbanization and Policy in Japan, South Korea and China, in Handbook of Urban Economics and Planning, "Oxford Press, UK, 2011.

[8] A. Z. Shao, "A strategic thought on the development of city and industry integration in yibin district of luoyang city, "Journal of Luoyang Institute of Science \& Technology, vol. 2, no. 1, pp. 101$109,2012$.

[9] X. Wu, "Green building design in Guangzhou area: understanding the green building evaluation standards," South Architecture, vol. 5, pp. 42-44, 2010

[10] C. L. Fang, and X. Q. Lin, "The spatial integration and industrial rationalization organization of Wuhan Urban agglomeration," Geographical Research, vol. 27, no. 2, pp. 397-408, 2008.

[11] Y. Zhang, Z. F. Yang, and L.Wei, "Measurement and evaluation of interactive relationships in urban complex ecosystem," Acta Ecologica Sinica, vol. 25, no. 7, pp. 1734-1740, 2005.

[12] Y. Lang, X. Dai and C. Wang, "Multi-index comprehensive evaluation model for the development capacity of urban complex and its application," Science \& Technology Progress \& Policy, vol. 30, no. 23, pp. 78-84, 2013.

[13] Y. E. Qi-Huan, L. I, Zhen-Hai, and M. A. Wei-Jun, "Economic and environmental benefits of CCHP for an urban complex simulation in Shanghai," Building Energy Efficiency, vol. 42, no. 2, pp. 95100, 2014.

[14] S. Huang, W. U. Qian-Bo, W. Z. Cui, "Development features and types of urban complex in the world," Economic Geography, vol. 33, no. 4, pp. 1-8, 2013.

[15] S. Li, and Q. Zhang, "High-Speed rail transportation hub development mode: from transport complex to urban complex," Planners, vol. 2, no. 2, pp. 110-120, 2011.

Received: June 10, 2015

(C) Zihan et al.; Licensee Bentham Open.

This is an open access article licensed under the terms of the (https://creativecommons.org/licenses/by/4.0/legalcode), which permits unrestricted, noncommercial use, distribution and reproduction in any medium, provided the work is properly cited. 